\title{
Rt-PA thrombolytic therapy in patients with acute posterior circulation stroke: A retrospective study
}

\author{
YAOZHI HU ${ }^{1}$, HAIFEI ZHENG ${ }^{2}$, XIAOHUI $\mathrm{CHEN}^{1}$ and $\mathrm{ZONGEN} \mathrm{GAO}^{1,3}$ \\ Departments of ${ }^{1}$ Neurology and ${ }^{2}$ International Special Needs Medicine, and ${ }^{3}$ Cardiovascular and Cerebrovascular Institute, \\ Shengli Oilfield Central Hospital, Dongying, Shandong 257000, P.R. China
}

Received November 29, 2021; Accepted February 28, 2022

DOI: $10.3892 / \mathrm{mi} .2022 .33$

\begin{abstract}
At present, recombinant tissue-type plasminogen activator (rt-PA) thrombolytic therapy is widely used in patients with acute ischemic stroke within $4.5 \mathrm{~h}$ following stroke onset. However, the efficacy of intravenous alteplase thrombolytic therapy for posterior circulation stroke (PCS) has been rarely described. The present study aimed to predict the outcome of patients with PCS following rt-PA thrombolytic therapy in a more efficient manner. Data were collected from patients who had suffered from posterior circulation ischemic stroke, who had been treated with rt-PA over a period of 4 years (2016-2020), and had been treated at a stroke center. All patients were treated with alteplase at a standard dose of $0.9 \mathrm{mg} / \mathrm{kg}$. According to the onset to needle time (ONT), these patients were divided into the 0-3 and 3-4.5 h groups, and the National Institutes of Health Stroke Scale (NIHSS) score was compared before thrombolysis and at $24 \mathrm{~h}$ after thrombolysis. Subsequently, the patients with acute PCS whose ONT was $\leq 3 \mathrm{~h}$ were divided into the NIHSS score $>3$ points and NIHSS score $\leq 3$ points groups, and the NIHSS score improvement rate was compared $24 \mathrm{~h}$ later. A total of 989 patients were included in the study; there were 783 patients with acute anterior circulation stroke (ACS) and 203 patients with acute PCS (of note, 2 patients had negative results from brain magnetic resonance imaging); 63 patients were treated with urokinase (UK) thrombolysis and 140 patients were treated with alteplase intravenous thrombolysis. The 140 patients that received alteplase thrombolytic therapy were divided into two groups, namely the $\leq 3 \mathrm{~h}$ group and 3-4.5 $\mathrm{h}$ group, which, on the basis of the ONT, no significant differences were found between the two the groups according to the NIHSS score before thrombolysis $(\mathrm{P}>0.05)$. The NHISS scores in the $\leq 3 \mathrm{~h}$ group were
\end{abstract}

Correspondence to: Dr Zongen Gao, Department of Neurology, Cardiovascular and Cerebrovascular Institute, Shengli Oilfield Central Hospital, 31 Jinan Road, Dongying, Shandong 257000, P.R. China

E-mail: gaozongen@126.com

Key words: rt-PA, posterior circulation stroke, thrombolytic therapy, onset to needle time, retrospective study significantly lower than those in the 3-4.5 h group following thrombolysis therapy, and the differences between the two groups were statistically significant $(\mathrm{P}<0.05)$; the patients with acute PCS treated with rt-PA in the $\leq 3 \mathrm{~h}$ group were divided into the NIHSS score $\leq 3$ points group and the NIHSS score $>3$ points group. In this $\leq 3 \mathrm{~h}$ group, the average NIHSS score improvement rate following rt-PA thrombolysis was 0.535 $(53.5 \%)$ in the NIHSS score $\leq 3$ points group and that in the NIHSS score $>3$ points group was $0.336(33.6 \%)$; the difference between the two groups was statistically significant $(\mathrm{P}<0.05)$. The patients treated with intravenous alteplase thrombolysis within $3 \mathrm{~h}$ following stroke onset benefited more than those treated with thrombolysis therapy within 3 to $4.5 \mathrm{~h}$ after stroke onset. On the whole, the present study demonstrates that the patients with mild stroke (NIHSS score $\leq 3$ points) who were treated at an earlier stage (received alteplase thrombolysis therapy within $3 \mathrm{~h}$ after stroke onset) benefited to a greater extent from the therapy.

\section{Introduction}

Acute ischemic stroke is a disease which is associated with a high morbidity, high mortality and high disability rate. Its occurrence also leads to a heavy economic burden to society, families and individuals (1). Therefore, the treatment of acute ischemic stroke is of particular importance. By improving cerebral blood flow and saving brain tissue, recombinant tissue-type plasminogen activator (rt-PA) is an effective clinical treatment approved by the Food and Drug Administration (FDA). However, due to the limited time window, only $2-5 \%$ of patients can receive rt-PA thrombolysis treatment (2). It has been demonstrated that thrombolysis therapy should be performed as early as possible, and every 15 min of treatment acceleration can improve the independent living ability of patients by $4 \%$ (3). Ischemic stroke can be divided into anterior circulation stroke (ACS) and posterior circulation stroke (PCS). Among all patients with ischemic stroke, patients with PCS account for 5-10\% (4). Of note, 5-19\% of patients with PCS have received intravenous alteplase thrombolytic therapy (5-8), and $36 \%$ of these patients can achieve a National Institutes of Health Stroke Scale (NIHSS) score $>25$ (9). Since studies on intravenous rt-PA thrombolysis in PCS are limited, the present retrospective study aimed to investigate whether the term 'time is brain' is relevant to PCS and whether patients 
with mild stroke receiving intravenous rt-PA thrombolysis within $3 \mathrm{~h}$ may benefit more than others.

\section{Patients and methods}

Patient selection and treatment. The present study was a single-center retrospective case study. Data were collected from patients who received rt-PA thrombolytic therapy at the Shengli Oilfield Central Hospital from January, 2016 to January, 2020, and the basic demographic characteristics and ischemic stroke-related data were included in this database. The present retrospective study was approved by the Shengli Oilfield Central Hospital Ethics Committee. As this was a retrospective study, the signing of relevant legal documents of informed consent was not required.

Clinical evaluation. Basic demographic data, including a history of hypertension, a history of type 2 diabetes mellitus, history of hyperlipidemia, history of smoking, history of alcohol consumption and a history of aspirin use $(100 \mathrm{mg} / \mathrm{day}$, the commonly used antiplatelet drugs for secondary prevention of cerebrovascular diseases are aspirin or clopidogrel, and the majority of patients in China use aspirin alone), and atrial fibrillation (AF; the patients enrolled in the study were patients treated with oral warfarin. The use of any direct oral anticoagulant drugs within $24 \mathrm{~h}$ prior to thrombolytic therapy was considered a contraindication. The enrolled patients with AF received an oral warfarin dose of $2.5-3 \mathrm{mg}$, and the International Normalized Ratio value was monitored every 5 days with a control range of 2.0-3.0). NIHSS scores were obtained upon admission, onset-to-needle time (ONT) and at $24 \mathrm{~h}$ following thrombolysis. A brain computed tomography (CT) scan prior to thrombolysis and at $24 \mathrm{~h}$ after thrombolysis is a routine examination. Routine examinations of serum homocysteine (Hcy) levels, which is related to H-type hypertension, were not performed (results for Hcy levels were not available in the data collected). The patients were treated with alteplase thrombolysis at a dose of $0.9 \mathrm{mg} / \mathrm{kg}$, and the maximum dose was not $>90 \mathrm{mg}$. At the beginning of thrombolysis, $10 \%$ of the total amount was administered by intravenous injection, and the remaining amount was pumped using a continuous micropump within $1 \mathrm{~h}$. Generally, if the patient has a cerebral hemorrhage following thrombolytic therapy, in order to prepare for surgery, the patient's coagulation function needs to be examined in order to guide the surgery, and often report the urgent value of prothrombin time and the activated partial thromboplastin time (APTT) index. A brain CT scan is generally reviewed within $24 \mathrm{~h}$ following intravenous thrombolytic therapy with alteplase. If there is no intracerebral hemorrhage, patients should be administered aspirin $(100 \mathrm{mg} /$ day $)+$ clopidogrel $(75 \mathrm{mg} /$ day $)$. This is consistent with the Chinese Guidelines for the Diagnosis and Treatment of Acute Ischemic Stroke 2018 (10).

Clinical outcome. All patients that received rt-PA thrombolysis therapy were divided into two groups, the 0-3 $\mathrm{h}$ (also termed the $\leq 3 \mathrm{~h}$ ) group and the $3-4.5 \mathrm{~h}$ group, in order to observe whether there were any differences in the NIHSS scores before thrombolysis and at $24 \mathrm{~h}$ after thrombolysis. In addition, the

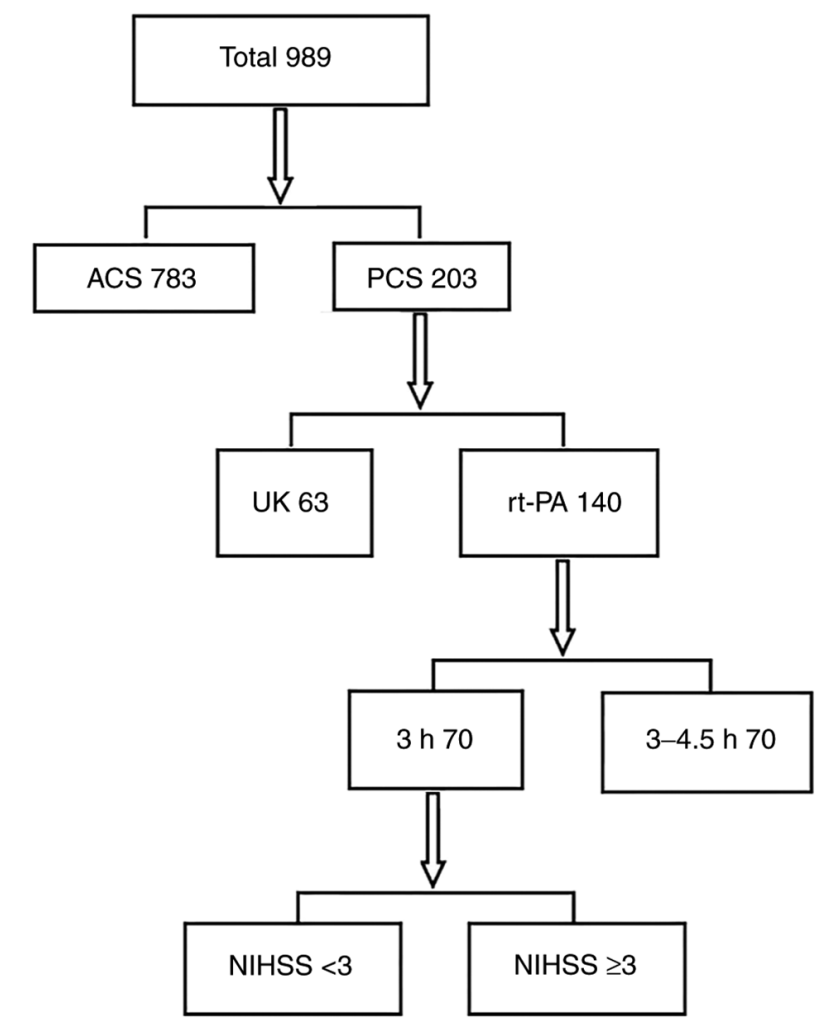

Figure 1. Diagram of the enrolment flow for the patients in the present study. Of note, 2 patients had negative results from brain magnetic resonance imaging. ACS, anterior circulation stroke; PCS, posterior circulation stroke; UK, urokinase; rt-PA, recombinant tissue-type plasminogen activator; NIHSS, National Institutes of Health Stroke Scale.

patients that received rt-PA thrombolysis in the 0-3 $\mathrm{h}$ group were divided into the NIHSS score $\leq 3$ group and the NIHSS score $>3$ group, and the improvement rate of the NIHSS score in the two groups was observed.

Statistical analysis. All statistical analyses were performed using SPSS 22.0 statistical software (SPSS, Inc.). Continuous data are presented as the mean \pm SD and statistically significant intergroup differences were assessed using a t-test. Quantitative variables are presented as a number and percentage [n (\%)] and statistically significant intergroup differences were assessed using the $\chi^{2}$ test and Fisher's exact test. A value of $\mathrm{P}<0.05$ was considered to indicate a statistically significant difference.

\section{Results}

From January, 2016 to January, 2020, a total of 989 patients with acute ischemic stroke received intravenous thrombolysis therapy at Shengli Oilfield Central Hospital. These included 783 patients with ACS and 203 patients with PCS (of note, 2 patients had negative results from brain magnetic resonance imaging). The present study aimed to observe patients with PCS. Of the 203 patients with PCS, 63 received thrombolytic therapy with urokinase (NS normal saline $100 \mathrm{ml}+$ one million $\mathrm{U}$ urokinase infusion pumped in $30 \mathrm{~min}$ ) and 140 patients received intravenous thrombolytic therapy with alteplase. Among these, 70 patients were included in the 0-3 h group and 70 patients were included in the 3-4.5 h group (Fig. 1). 
Table I. Demographic profiling and risk factors in patients with PCS.

\begin{tabular}{|c|c|c|c|}
\hline Baseline variables & ONT $(0-3 \mathrm{~h}), \mathrm{n}=70$ & ONT (3-4.5 h), n=70 & P-value \\
\hline \multicolumn{4}{|l|}{ Demographics } \\
\hline Male & $50(71.4 \%)$ & $50(71.4 \%)$ & ns \\
\hline Age, years & $62.90 \pm 11.30$ & $65.57 \pm 11.66$ & 0.171 \\
\hline \multicolumn{4}{|l|}{ Risk factors } \\
\hline Hypertension & $46(65.7 \%)$ & $45(64.3 \%)$ & 0.859 \\
\hline Diabetes mellitus & $18(25.7 \%)$ & $26(37.1 \%)$ & 0.145 \\
\hline Hyperlipidemia & $4(5.7 \%)$ & $2(2.9 \%)$ & 0.340 \\
\hline Coronary artery disease & $12(17.1 \%)$ & $15(21.4 \%)$ & 0.520 \\
\hline Atrial fibrillation & $4(5.7 \%)$ & $3(4.3 \%)$ & 0.500 \\
\hline Smoking & $25(35.7 \%)$ & $25(35.7 \%)$ & ns \\
\hline History of alcohol consumption ${ }^{\mathrm{a}}$ & $17(24.3 \%)$ & $19(27.1 \%)$ & 0.699 \\
\hline History of oral aspirin use & $11(15.7 \%)$ & $11(15.7 \%)$ & ns \\
\hline $\mathrm{DNT}(\min )$ & $74.13 \pm 32.12$ & $84.34 \pm 37.82$ & 0.093 \\
\hline ONT (min) & $131.72 \pm 34.88$ & $229.58 \pm 24.07$ & 0.01 \\
\hline Baseline NIHSS score & $6.63 \pm 6.94$ & $8.0 \pm 8.62$ & 0.302 \\
\hline NIHSS score ( $24 \mathrm{~h}$ after thrombolysis) & $3.78 \pm 4.22$ & $6.70 \pm 9.17$ & 0.016 \\
\hline
\end{tabular}

Data were analyzed using the Chi-squared test of Fisher's exact test (for values for dyslipidemia and atrial fibrillation). ${ }^{a}$ History of alcohol consumption refers to the consumption of $>50 \mathrm{~g}$ alcohol daily for $>1$ month. DNT, door to needle time; NIHSS, National Institutes of Health Stroke Scale; ONT, onset to needle time; PCS, posterior circulation stroke.

Table II. Demographic profiling and risk factors in patients with PCS (ONT $\leq 3 \mathrm{~h})$.

\begin{tabular}{lcc}
\hline Baseline variables & NIHSS score $\leq 3, \mathrm{n}=33$ & NIHSS score $>3, \mathrm{n}=37$ \\
\hline Demographics & & P-value \\
Male & $23(69.7 \%)$ & $27(73.0 \%)$ \\
Age, years & $63.00 \pm 10.15$ & $67.86 \pm 12.56$ \\
Risk factors & & 0.081 \\
Hypertension & $21(63.6 \%)$ & 0.729 \\
Diabetes mellitus & $12(36.4 \%)$ & 0.054 \\
Hyperlipidemia & $1(3.0 \%)$ & 0.352 \\
Coronary artery disease & $6(18.2 \%)$ & 0.828 \\
Atrial fibrillation & $2(6.0 \%)$ & $3(8.1 \%)$ \\
Smoking & $8(24.2 \%)$ & $6(16.2 \%)$ \\
History of alcohol consumption ${ }^{\mathrm{a}}$ & $6(18.2 \%)$ & $3(8.1 \%)$ \\
History of oral aspirin use & $6(18.2 \%)$ & $17(45.9 \%)$ \\
DNT (min) & $66.37 \pm 34.74$ & $11(29.7 \%)$ \\
ONT (min) & $130.34 \pm 42.14$ & $5(13.5 \%)$ \\
NIHSS score improvement rate $(24 \mathrm{~h}$ after thrombolysis) & 0.5354 & 0.059 \\
\hline
\end{tabular}

Data were analyzed using the Chi-squared test of Fisher's exact test (for values for dyslipidemia, atrial fibrillation and history of oral aspirin

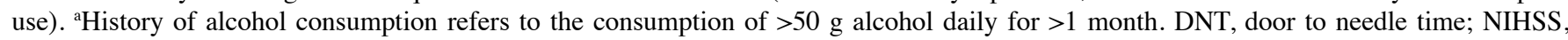
National Institutes of Health Stroke Scale; ONT, onset to needle time; PCS, posterior circulation stroke.

No statistically significant differences were observed between the two groups as regards age, sex, history of hypertension, history of diabetes mellitus, history of hyperlipidemia, smoking history and history of aspirin use, and there were no significant differences in the NIHSS scores between the two groups before thrombolysis. Following thrombolysis therapy, the NIHSS score of the two groups was statistically analyzed (the NIHSS score in the $0-3 \mathrm{~h}$ group was $3.78 \pm 4.22$ and that

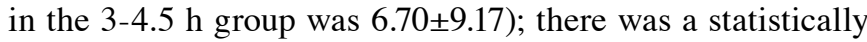
significant difference between the two groups $(\mathrm{P}<0.05$; Table I).

The patients in the 0-3 h group who received rt-PA intravenous thrombolysis were then divided into the NIHSS score $>3$ 
group and NIHSS score $\leq 3$ group. No statistically significant differences were observed between the two groups as regards age, sex, history of hypertension, history of diabetes mellitus, history of hyperlipidemia, smoking history and history of aspirin use. The improvement rate in the NIHSS score was examined prior to thrombolysis therapy and at $24 \mathrm{~h}$ after intravenous thrombolysis therapy; the comparison between the two groups revealed that the improvement rate in the NIHSS score $\leq 3$ group was high (the improvement rate in the NIHSS score $>3$ group was $33.6 \%$, and that in the NIHSS score $\leq 3$ group was 53.5\%); the difference was statistically significant $(\mathrm{P}<0.05$; Table II).

\section{Discussion}

The present retrospective study demonstrated that patients with PCS could benefit more from intravenous thrombolysis performed at an earlier stage. In addition, in patients with mild stroke who received intravenous thrombolysis therapy at an earlier stage, the improvement rate was more pronounced. Some researchers have found that the risk of bleeding following intravenous rt-PA thrombolysis in PCS (RR 0.49) is significantly lower than that in ACS (11). A previous study in China also found that the safety and efficacy of intravenous thrombolysis in patients with PCS was also higher than that in patients with ACS (12). It is important to determine the risk of bleeding following intravenous thrombolysis in PCS. The Get With the Guidelines Stroke (GWTG-S) Registry found that the probability of bleeding after intravenous rt-PA thrombolysis in PCS was $4.4 \%$, and the probability in China was 4.87-7.3\% (13-15). All patients in the present study did not suffer from intracerebral hemorrhage following intravenous thrombolysis therapy. Of note, the probability of intracerebral hemorrhage after thrombolysis in patients with PCS is lower than that in those with ACS. In addition, the NIHSS score can indicate more severe conditions, and patients who require thrombolysis + intravascular interventional therapy are admitted to neurology intensive care units. However, from the perspective of pathogenesis, the question remains as to why the probability of the occurrence of intracerebral hemorrhage after thrombolysis therapy in PCS is lower than that in ACS. The small volume of the infarction and the posterior circulation supplied by bilateral vertebral arteries are considered to be related $(16,17)$.

In the present study, in the patients who received thrombolysis, a NIHSS score of 3 was considered as the threshold for patients with mild stroke. However, it remains to be confirmed whether it is reasonable to use a NIHSS score of 3 as the threshold. Currently, there is no clear definition of mild stroke. Some researchers have indicated that mild stroke refers to patients with a NIHSS score of 0-5 (18). Of note however, other researchers have defined mild stroke as a NIHSS score of 0-3 (19). Thus, there remains some discrepancy as to the definition of mild stroke. A number of symptoms of PCS cannot be scored and measured using the NIHSS score (20), such as dizziness and walking instability. In addition, the NIHSS score may be low in PCS, and it may not fully reflect the actual condition of the disease. The present study mainly introduced acute PCS. Therefore, mild stroke was defined as a patient with a NIHSS score of $<3$.
The present retrospective study analyzed the NIHSS scores before thrombolysis and at $24 \mathrm{~h}$ after thrombolysis therapy, which provides evidence for emergency rt-PA thrombolysis following admission for acute PCS. Currently, early neurological deterioration (END) has been put forward as a concept (21). The NIHSS score $24 \mathrm{~h}$ after thrombolysis and a NIHSS score at the time of intravenous thrombolysis of $>4$ met the definition of END (22). In the present study, among the 140 patients with PCS who received rt-PA treatment, 5 patients met the definition of END $24 \mathrm{~h}$ after receiving thrombolysis therapy. However, it appears that a NIHSS score of $<4$ is also meaningful for patients with mild stroke (23). It was previously reported that the incidence of END was $16.3 \%$ (24) and $17.6 \%$ (25), respectively. A recent large cohort study calculated the incidence of END as 6\% (26), and the probability of END in the present study was $3.6 \%$. The reason may be that the present retrospective study only examined patients with PCS, and only examined the patients within $4.5 \mathrm{~h}$ of onset. In addition, some patients with higher NIHSS scores were directly admitted to the Neurology Intensive Care Unit of our hospital. Therefore, the probability of the occurrence of END in the present study was lower than that of other studies. For patients who were receive rt-PA thrombolysis therapy, the incidence of END caused by symptomatic cerebral hemorrhage accounts for $\sim 20 \%$ (27). In addition, it has also been noted that the edema following thrombolysis can also lead to the occurrence of END. Currently, $70 \%$ of cases of END are of unknown cause (28).

The present study had a number of limitations. Firstly, there were a number of patients with mild or rapidly improved stroke who did not receive intravenous thrombolysis treatment, although they were within the intravenous thrombolysis window time frame. In previous studies on such patients who were treated with intravenous thrombolysis, the outcome was not shown to markedly improve (29); however, other studies have demonstrated a significant improvement in such patients who were received this treatment (30). In the present study, a higher proportion of these patients should have received rt-PA intravenous thrombolysis. Secondly, the patients were not followed-up for the first three months; thus, to date, it cannot be determined whether there were any adverse conditions or a repeat of symptoms. Thirdly, there was some bias in the inclusion of patients in the present study. The present study did not include patients with cardiogenic cerebral infarction, particularly those with posterior circulation cerebral infarction. In such patients, the disease is severe and the NIHSS score is high. Such patients were directly admitted to the neurological intensive care unit of our hospital. Furthermore, some patients received mechanical recanalization therapy and were thus not included, and finally, the number of patients with atrial fibrillation was minimal in the present study. Patients who received mechanical thrombectomy therapy were also excluded. Finally, the present retrospective study was a single-center study; thus, some of the data may not be accurate for all patients.

In conclusion, the present retrospective study found that patients with acute PCS could benefit more from early-stage intravenous thrombolysis therapy. In addition, in patients who received intravenous rt-PA thrombolysis within $3 \mathrm{~h}$ of the onset of ischemic stroke, it was found that the milder ischemic stroke, the more prominent he improvement. 


\section{Acknowledgements}

Not applicable.

\section{Funding}

The present study WAS supported by the ChinaKey RESEARCH and Development Program (grant no. 2016YFC1301502).

\section{Availability of data and materials}

The datasets used and/or analyzed during the current study are available from the corresponding author on reasonable request.

\section{Authors' contributions}

All authors (YH, HZ, XC and ZG) contributed to the study conception and design. Material preparation, data collection, experiment design, experiment implementation and analysis were performed by ZG. YH wrote the first draft of the manuscript. XC and $\mathrm{HZ}$ confirm the authenticity of all the raw data. All authors have read and approved the final manuscript.

\section{Ethics approval and consent to participate}

The present retrospective study was approved by the Shengli Oilfield Central Hospital Ethics Committee. As this was a retrospective study, the signing of relevant legal documents of informed consent was not required.

\section{Patient consent for publication}

Not applicable.

\section{Competing interests}

The authors declare that they have no competing interests.

\section{References}

1. Writing Group Members; Mozaffarian D, Benjamin EJ, Go AS Arnett DK, Blaha MJ, Cushman M, Das SR, de Ferranti S, Després JP, et al: Executive summary: Heart disease and stroke statistics-2016 update: A report from the American heart association. Circulation 133: 447-454, 2016.

2. Roth JM: Recombinant tissue plasminogen activator for the treatment of acute ischemic stroke. Proc (Bayl Univ Med Cent) 24 257-259, 2011.

3. Saver JL, Fonarow GC, Smith EE, Reeves MJ, Grau-Sepulveda MV, Pan W, Olson DM, Hernandez AF, Peterson ED and Schwamm LH: Time to treatment with intravenous tissue plasminogen activator and outcome from acute ischemic stroke. JAMA 309: 2480-2488, 2013.

4. Mazya MV, Lees KR, Collas D, Rand VM, Mikulik R, Toni D, Wahlgren $\mathrm{N}$ and Ahmed N: IV thrombolysis in very severe and severe ischemic stroke: Results from the SITS-ISTR Registry. Neurology 85: 2098-2106, 2015.

5. Sung SF, Chen CH, Chen YW, Tseng MC, Shen HC and Lin HJ: Predicting symptomatic intracerebral hemorrhage after intravenous thrombolysis: Stroke territory as a potential pitfall. J Neurol Sci 335: 96-100, 2013.

6. Forster A, Gass A, Kern R, Griebe M, Hennerici MG and Szabo K: Thrombolysis in posterior circulation stroke: Stroke subtypes and patterns, complications and outcome. Cerebrovasc Dis 32: 349-353, 2011
7. Dornak T, Král M, Hazlinger M, Herzig R, Veverka T, Buřval S, Šaňák D, Zapletalová J, Antalíková K and Kaňovský P: Posterior vs. anterior circulation infarction: Demography, outcomes, and frequency of hemorrhage after thrombolysis. Int J Stroke 10: 1224-1228, 2015.

8. Breuer L, Huttner HB, Jentsch K, Blinzler C, Winder K, Engelhorn $\mathrm{T}$ and Köhrmann M: Intravenous thrombolysis in posterior cerebral artery infarctions. Cerebrovasc Dis 31: 448-454, 2011.

9. Sarikaya H, Arnold M, Engelter ST, Lyrer PA, Mattle HP, Georgiadis D, Bonati LH, Fluri F, Fischer U, Findling O, et al: Outcomes of intravenous thrombolysis in posterior versus anterior circulation stroke. Stroke 42: 2498-2502, 2011.

10. Chinese Society of Neurology, Chinese Stroke Society: Chinese Guidelines for the Diagnosis and Treatment of Acute Ischemic Stroke 2018. Chin J Neurol 51: 666-682, 2018.

11. Keselman B, Gdovinová Z, Jatuzis D, Melo TPE, Vilionskis A, Cavallo R, Frol S, Jurak L, Koyuncu B, Nunes AP, et al: Safety and outcomes of intravenous thrombolysis in posterior versus anterior circulation stroke: Results from the safe implementation of treatments in stroke registry and meta-analysis. Stroke 51: 876-882, 2020.

12. Tong X, Liao X, Pan Y, Cao Y, Wang C, Liu L, Zheng H, Zhao X, Wang C, Wang Y, et al: Intravenous thrombolysis is more safe and effective for posterior circulation stroke: Data from the thrombolysis implementation and monitor of acute ischemic stroke in China (TIMS-China). Medicine (Baltimore) 95: e3848, 2016.

13. Kim JT, Fonarow GC, Smith EE, Reeves MJ, Navalkele DD, Grotta JC, Grau-Sepulveda MV, Hernandez AF, Peterson ED, Schwamm LH and Saver JL: Treatment with tissue plasminogen activator in the golden hour and the shape of the 4.5-hour time-benefit curve in the National United States get with the guidelines-stroke population. Circulation 135: 128-139, 2017.

14. Liu M, Pan Y, Zhou L and Wang Y: Predictors of postthrombolysis symptomatic intracranial hemorrhage in Chinese patients with acute ischemic stroke. PLoS One 12: e0184646, 2017.

15. Guo Y, Yang Y, Zhou M and He L: Risk factors of haemorrhagic transformation for acute ischaemic stroke in Chinese patients receiving intravenous recombinant tissue plasminogen activator: A systematic review and meta-analysis. Stroke Vasc Neurol 3: 203-208, 2018

16. Lindgren A, Norrving B, Rudling $\mathrm{O}$ and Johansson BB: Comparison of clinical and neuroradiological findings in first-ever stroke. A population-based study. Stroke 25: 1371-1377, 1994.

17. Menon BK, O'Brien B, Bivard A, Spratt NJ, Demchuk AM, Miteff F, Lu X, Levi C and Parsons MW: Assessment of leptomeningeal collaterals using dynamic CT angiography in patients with acute ischemic stroke. J Cereb Blood Flow Metab 33: 365-371, 2013.

18. Logallo N, Kvistad CE, Naess H, Waje-Andreassen U and Thomassen L: Mild stroke: Safety and outcome in patients receiving thrombolysis. Acta Neurol Scand Suppl 37-40, 2014.

19. Willey JZ, Khatri P, Khoury JC, Merino JG, Ford AL, Rost NS, Gonzales NR, Ali LK, Meyer BC and Broderick JP: Variability in the use of intravenous thrombolysis for mild stroke: Experience across the SPOTRIAS network. J Stroke Cerebrovasc Dis 22: 318-322, 2013.

20. Sato S, Toyoda K, Uehara T, Toratani N, Yokota C, Moriwaki H, Naritomi H and Minematsu K: Baseline NIH Stroke scale score predicting outcome in anterior and posterior circulation strokes. Neurology 70 (24 Pt 2): 2371-2377, 2008.

21. Siegler JE and Martin-Schild S: Early neurological deterioration (END) after stroke: The END depends on the definition. Int J Stroke 6: 211-212, 2011.

22. Seners P, Turc G, Oppenheim C and Baron JC: Incidence, causes and predictors of neurological deterioration occurring within $24 \mathrm{~h}$ following acute ischaemic stroke: A systematic review with pathophysiological implications. J Neurol Neurosurg Psychiatry 86: 87-94, 2015.

23. Saver JL, Gornbein J and Starkman S: Graphic reanalysis of the two NINDS-tPA trials confirms substantial treatment benefit. Stroke 41: 2381-2390, 2010

24. Alexandrov AV, Felberg RA, Demchuk AM, Christou I, Burgin WS, Malkoff M, Wojner AW and Grotta JC: Deterioration following spontaneous improvement: Sonographic findings in patients with acutely resolving symptoms of cerebral ischemia. Stroke 31: 915-919, 2000 
25. Grotta JC, Welch KM, Fagan SC, Lu M, Frankel MR, Brott T, Levine SR and Lyden PD: Clinical deterioration following improvement in the NINDS rt-PA stroke trial. Stroke 32: 661-668, 2001.

26. Simonsen CZ, Schmitz ML, Madsen MH, Mikkelsen IK, Chandra RV, Leslie-Mazwi T and Andersen G: Early neurological deterioration after thrombolysis: Clinical and imaging predictors. Int J Stroke 11: 776-782, 2016.

27. Kim JM, Moon J, Ahn SW, Shin HW, Jung KH and Park KY: The etiologies of early neurological deterioration after thrombolysis and risk factors of ischemia progression. J Stroke Cerebrovasc Dis 25: 383-388, 2016.

28. Seners P, Turc G, Tisserand M, Legrand L, Labeyrie MA, Calvet D, Meder JF, Mas JL, Oppenheim C and Baron JC: Unexplained early neurological deterioration after intravenous thrombolysis: Incidence, predictors, and associated factors. Stroke 45: 2004-2009, 2014.
29. Frank B, Grotta JC, Alexandrov AV, Bluhmki E, Lyden P, Meretoja A, Mishra NK, Shuaib A, Wahlgren NG, Weimar C, et al: Thrombolysis in stroke despite contraindications or warnings? Stroke 44: 727-733, 2013.

30. Yeo LLL, Ho R, Paliwal P, Rathakrishnan R and Sharma VK: Intravenously administered tissue plasminogen activator useful in milder strokes? A meta-analysis. J Stroke Cerebrovasc Dis 23: 2156-2162, 2014

(i)(9) This work is licensed under a Creative Commons Attribution-NonCommercial-NoDerivatives 4.0 International (CC BY-NC-ND 4.0) License. 